\title{
Age specific prevalence of impairment and disability relating to hemiplegic stroke in the Hai District of northern Tanzania
}

Richard W Walker, Donald G McLarty^, Gabriel Masuki, Henry M Kitange, David Whiting, Adess F Moshi, John G Massawe, Richard Amaro, Ali Mhina, K G M M Alberti, on behalf of the Adult Morbidity and Mortality Project

Department of Medicine, North Tyneside General Hospital, Rake Lane, North Shields, Tyne and Wear, NE29 $8 \mathrm{NH}$, UK

R W Walker

Department of Medicine, Medical School, University of Newcastle upon Tyne D G McLarty*

K G M M Alberti

Ministry of Health, PO Box 9083, Dar-es-Salaam, Tanzania G Masuki H M Kitange

Adult Morbidity and Mortality Project (AMMP), PO Box 65243, Dar-es-Salaam, Tanzania

D Whiting

A F Moshi

J G Massawe

R Amaro

A Mhina

Correspondence to: Dr R W Walker

R.W.WALKER@ncl.ac.uk.

Received 21 May 1999 and in revised form

8 September 1999

Accepted 29 October 1999

${ }^{\star}$ Deceased

\begin{abstract}
Objectives-To determine the age specific prevalence of impairment and disability relating to hemiplegic stroke in one rural area of Tanzania.

Methods-During the yearly house to house census of the study population of 148135 (85 152 aged 15 and over) in August 1994, specific questions were asked to identify those who might be disabled from stroke. People thus identified were subsequently interviewed and examined by one investigator. In those in whom the clinical diagnosis of stroke was confirmed a more detailed interview and examination relating to risk factors and recovery was carried out.

Results-One hundred and eight patients, 61 men and 47 women, were identified with a median age of 70 (range 18-100). Median age at first stroke was 65 years. The age specific rates in this study were lower than previous studies in developed countries. All were cared for at home although $23(21 \%)$ were bedbound.

Conclusions-Although prevalence of impairment and disability related to stroke in this population as a whole was low this is mainly explained by the age structure, with less than $6 \%$ being aged 65 and over. Age standardised rates for stroke with residual disability were about half those found in previous studies in developed countries. Death from stroke in Africa may be higher but data are limited. With the demographic transition stroke is likely to become a more important cause of disability in sub-Saharan Africa.

(F Neurol Neurosurg Psychiatry 2000;68:744-749)
\end{abstract}

Keywords: stroke; disability; sub-Saharan Africa

Stroke is both the third most common cause of death in the United Kingdom and a major cause of morbidity. ${ }^{1}$ Previous epidemiological studies have mainly concentrated on incidence but, as many stroke patients survive with some disability for many years, the impact of stroke on the community is best assessed by prevalence studies. ${ }^{2}$ In terms of burden of disease overall prevalence is, however, a less useful measure than estimates that are limited to patients with incomplete recovery. ${ }^{3}$

Most studies of stroke prevalence in developed countries have adopted a screening ques- tionnaire for case finding. Studies from the developed world have estimated prevalences of 410-715/100 000..$^{4-8}$ One study from Sicily ${ }^{9}$ used a house to house survey and found 771 strokes in a population of 24 496. Most studies in developing countries have used house to house surveys. A prevalence study of 14010 Parsis living in Bombay showed 842 cases/100 $000,{ }^{10}$ whereas in rural Kashmir only 143/ 100000 were found. ${ }^{11}$ This study was not limited to stroke but used a World Health Organisation (WHO) protocol to look at the prevalence of neurological disorders in general. One problem, when comparing these studies, is that diagnostic criteria and case selection differ between studies.

In developed countries stroke is mainly a problem of elderly people. In the Oxfordshire Community Stroke Project (OCSP) ${ }^{12}$ only $8 \%$ of strokes occurred in those aged 54 and under. However, this is not true of developing countries where many fewer survive to old age and it is therefore important when comparing prevalence world wide to look at age specific or age adjusted prevalence.

There have been very few studies on stroke in sub-Saharan Africa and almost all are hospital based, which reflect only those people who manage to reach hospital. Community based research in developing countries, where many people do not have contact with formal medical services, is not easy to perform. The aids to such a study in developed countries, such as postal addresses, postcodes, and phone numbers are very much the exception rather than the rule. The aim of this study was to estimate the impact of stroke, in terms of impairment and disability, in a rural area of Tanzania.

\section{Methods}

The Hai district is one of the three project areas of the Tanzanian Adult Morbidity and Mortality Project (AMMP) and is situated in the Kilimanjaro region of northern Tanzania. ${ }^{13}$ The project area is almost entirely rural and most of the population live on the slopes of Kilimanjaro, where people are mainly of the Chagga tribe and Christian. They live on shambas (a small area of land that is cultivated around the house), where subsistence crops and also cash crops, such as coffee, are grown. Most are not in paid employment. Among the population living in the less fertile plains several different tribes are represented and a high proportion are Muslims. 
Each village in Hai has an "enumerator", usually a nurse or a teacher, who has received specific training and is responsible for data collection.

In the yearly census carried out in July and August of 1994 (population 148 135) three questions were included to try to identify anyone in the household who might be disabled from a stroke. These questions were:

(1) Is there anyone in the household with a history of stroke?

(2) Is there anyone in the household with a weakness down one side of the body?

(3) Does anyone in the household require assistance with: (a) dressing, (b) eating,

(c) toileting?

The aims of the study and the specific questions were explained in a workshop to the enumerators and the four medical assistant supervisors. Information was given on risk factors, mechanisms, and consequences of stroke and the sort of residual disability they might find. A further workshop was held during the early days of the field work which commenced in December 1994.

All people identified with a possible history of hemiplegic stroke by a positive answer to one or more of the screening questions, were seen in their own homes, and a diagnosis was established by one of us (RWW), with extensive experience of stroke, on history (including any treatment) and examination, bearing in mind other possible causes of hemiplegia. If the diagnosis was confirmed a detailed questionnaire was completed relating to the history of the stroke, history, potential risk factors, family history, and social circumstances. Whether blood pressure had ever been measured, or whether there was any history of a diagnosis of hypertension being made and any treatment given, was recorded. Use of medical services and carer support was also recorded. The interviews were conducted in either Swahili or Chagga (or very occasionally English) with the medical assistant supervisors acting as interpreters. A general medical and neurological examination was conducted on each patient and a Barthel score recorded. Where possible, the diagnosis was confirmed from the original hospital case notes.

Stroke was defined according to the WHO definition "rapidly developing clinical signs of focal (or global) disturbance of cerebral function with symptoms lasting 24 hours or longer or leading to death, with no apparent cause other than vascular origin". ${ }^{14}$

Many people did not know their exact year of birth. Where necessary, recognised methods using estimated age at significant times in Tanzania's history (for example, the second world war and independence) were used to estimate age.

Repeated surveys by the enumerators continued to identify patients until 14 April 1995, which was taken as the cut off point for stroke related disability point prevalence. Any previously identified patients who had died by this time were excluded from the study. The following additional secondary measures were also taken to try to ensure as complete case ascertainment as possible:

(1) Medical ward admission books were checked at the four main local hospitals. In the two larger hospitals it was possible to check records for the previous 15 years to identify anyone who had been admitted with a stroke. If available, the hospital notes were reviewed for these cases.

For any patients identified who had not died in hospital and who we had not already been seen, details were given to the enumerators to try to trace the surviving patients.

(2) One or two of the larger health centres looked after inpatients and admission books were checked where possible.

(3) Physiotherapy records were also checked, both at the local hospitals and within the local community based rehabilitation project.

\section{Results}

The total study population comprised 70955 males and 77180 females, with 39458 and 45 694 respectively aged 15 and over. Two people, in whom the history from the relatives suggested a stroke, had moved from the area between the time of the census and the time of the study, and three had died. Five people gave a history suggestive of stroke but on examination had made a full recovery. Four people were identified subsequent to the census but before the date for point prevalence of impairment and disability and were therefore included. No one under the age of 15 was identified as having had a stroke.

Other causes of hemiplegia identified in persons over the age of 10 were febrile illness in childhood (28) including meningitis and measles, cerebral malaria (10), cerebral palsy (27), head injury (seven), polio with upper and lower limb involvement (two), likely cranial space occupying lesion (two), hydrocephalus (three) (all with bilateral signs), and near drowning in one giving a total of 80 cases.

A total of 108 people were identified as fitting the criteria for the study. In only 14 of those included in the study were actual hospital records identified although more names were identified from ward admission books. Of the new people identified from hospital records five, when subsequently reviewed, had made a complete recovery and the remainder had died after discharge. Only 13 gave a history of having had any contact with physiotherapy services since their discharge from hospital and only five of these were identified from physiotherapy records. No new persons were identified from the health centres or physiotherapy records.

There were 61 men and 47 women. The median age for both sexes was 70 years (range $18-100)$. Median age at the time of first stroke was 65 years (range 15-100) (men 66 years; women 65 years). Thirty (49\%) men were 65 years and older compared with $33(70 \%)$ women, and 11 of the 15 over 85 were men. Age specific rates of prevalence are shown in table 1. Table 2 shows age specific rates for those requiring help in at least one activity of daily living. 
Table 1 Age specific rates of prevalence of disability resulting from stroke 1100000 for men and women in Hai district aged 15 and over

\begin{tabular}{|c|c|c|c|c|c|c|}
\hline \multirow{2}{*}{$\begin{array}{l}\text { Age bands } \\
\text { (y) }\end{array}$} & \multicolumn{2}{|c|}{ Strokes (n) } & \multicolumn{2}{|c|}{$\begin{array}{l}\text { Population } \\
\text { denominator }\end{array}$} & \multicolumn{2}{|c|}{$\begin{array}{l}\text { Crude rates } / 100000 \text { population } \\
(95 \% \text { CI) }\end{array}$} \\
\hline & Males & Females & Males & Females & Males & Females \\
\hline $15-24$ & 2 & 1 & 12981 & 14873 & $15(0-37)$ & $7(0-20)$ \\
\hline $25-34$ & 0 & 1 & 8137 & 10287 & 0 & $10(0-28)$ \\
\hline $35-44$ & 4 & 3 & 5844 & 7228 & $68(1-135)$ & $41(0-88)$ \\
\hline $45-54$ & 5 & 1 & 4467 & 5169 & $112(14-210)$ & $19(0-57)$ \\
\hline $55-64$ & 10 & 8 & 3925 & 3838 & $255(97-412)$ & $208(64-353)$ \\
\hline $65-74$ & 19 & 16 & 2477 & 2443 & $767(423-1111)$ & 655 (335-975) \\
\hline $75-84$ & 10 & 13 & 1158 & 1235 & $864(331-1396)$ & $1053(483-1622)$ \\
\hline $85+$ & 11 & 4 & 469 & 521 & $2345(976-3715)$ & $768(18-1517)$ \\
\hline \multicolumn{5}{|c|}{ Age standardised ${ }^{\star}$} & $154^{\star}$ & $114^{\star}$ \\
\hline
\end{tabular}

^Age standardised to the Segi World Population 15 years and above.

Table 2 Age specific rates of prevalence of disability resulting from stroke/100 000 for men and women in Hai district aged 15 and over, showing only those requiring help with at least one activity of daily living

\begin{tabular}{|c|c|c|c|c|}
\hline \multirow[b]{2}{*}{ Age bands (y) } & \multicolumn{2}{|c|}{ Strokes $(n)$} & \multicolumn{2}{|c|}{ Crude rates $/ 100000$ population ( $95 \%$ CI) } \\
\hline & Males & Females & Males & Females \\
\hline $15-24$ & 1 & 0 & $8(0-23)$ & 0 \\
\hline $25-34$ & 0 & 1 & 0 & $10(0-29)$ \\
\hline $35-44$ & 0 & 2 & 0 & $28(0-66)$ \\
\hline $45-54$ & 2 & 1 & $39(0-101)$ & $19(0-57)$ \\
\hline $55-64$ & 5 & 7 & $127(16-239)$ & $182(47-317)$ \\
\hline $65-74$ & 7 & 12 & $283(73-492)$ & $491(214-768)$ \\
\hline $75-84$ & 5 & 11 & $604(227-982)$ & $891(367-1415)$ \\
\hline $85+$ & 8 & 3 & $1706(534-2878)$ & $576(0-1225)$ \\
\hline Age standardised ${ }^{\star}$ & & & $69 \star$ & $90^{\star}$ \\
\hline
\end{tabular}

*Age standardised to the Segi World Population 15 years and above.

The calculated prevalence/100 000 for the whole population (148 135) was 73 , whereas for those aged 15 and over $(85152)$ it was 127 (155 for men and 103 for women). The prevalence for those aged 55 and over was 566, with 623 for men and 510 for women. The rate for those aged 65 and over was 876 , with 975 for men and 786 for women.

All but two had been born and brought up in Hai district and all had spent their adult life living there except for three who had travelled with their work at times.

There was no history of hypertension in 69 patients, of whom 61 had never had their blood pressure measured. Of the 25 taking antihypertensive drugs at the time of their stroke four had been on treatment for less than 1 year; 11 further patients had defaulted from treatment, five within the year before stroke. Three patients had been diagnosed to be hypertensive at some stage but had never received treatment. Of the 40 who had had their blood pressure measured in the year before their stroke only 14
(35\%) had had this measured more often than every 3 months.

After the stroke 56 (52\%) received treatment for high blood pressure at some time. However, after discharge from hospital (or after the stroke in those not admitted) 44 (41\%) had never had their blood pressure measured whereas seven $(6 \%)$ had only had it measured once. Of the remainder only $20(19 \%)$ had had their blood pressure measured at least monthly.

Seven had had a previous stroke and one a transient ischaemic attack. Two gave a history of angina and one a history of claudication. Type II diabetes mellitus was present in three. Two were pregnant at the time of their stroke. Sixteen were current smokers and $11 \mathrm{ex}-$ smokers. Only one was taking aspirin regularly before the stroke and only one after the stroke.

All of the patients were fully independent with maximum Barthel scores before their first stroke. Territory of stroke was right carotid in 67 , left carotid in 40 , and bilateral in one. No patients with involvement of the posterior circulation were identified but these patients are much more difficult to identify on screening.

At the time of examination $80(74 \%)$ had no dysarthria, 15 slight slurring, six (6\%) were difficult to understand, four were incomprehensible, and three were aphasic. Only one had impaired swallowing. Visual fields were normal in $76(70 \%)$, with homonymous hemianopia or visual inattention in $20(19 \%)$ whereas it was impossible to assess the remaining 12 . Twenty three $(21 \%)$ were bedbound, $12(11 \%)$ chairbound, 12 (11\%) housebound, 53 (49\%) had limited mobility, and eight were independently mobile.

The figure shows the percentages of men and women dependent for activities of daily living as assessed by the Barthel score. Median Barthel score was 17 and 37 had a Barthel total of $<10$.

Forty one (40\%) were independent for washing, dressing, bathing, feeding, transferring, or toileting, the criteria used to define "assistance in at least one self care activity" in the Auckland study. ${ }^{3}$ Median age for this group was 67 years (range 18-92 years) whereas median age at first stroke for this group was 58 years (range 15-90 years). This independent group included $31(51 \%)$ of the men and only $10(21 \%)$ of the women.

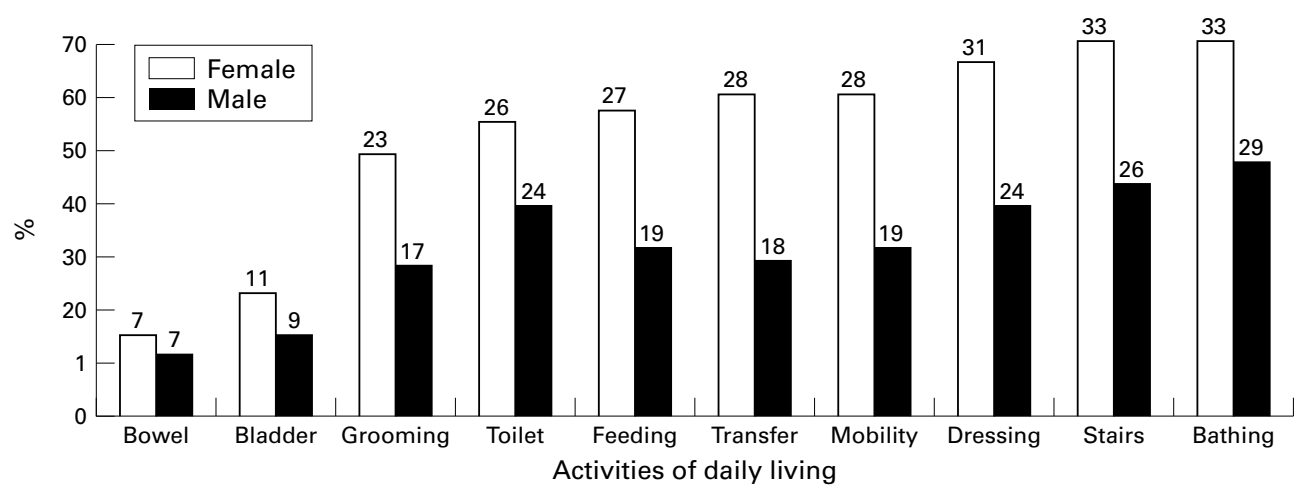

Figure 1 Age specific rates of prevalence of impairment and disability (\%) by sex with actual numbers shown. 
Discussion

This type of study is difficult to perform in rural Africa. A conventional prevalence study would include persons who had ever had a stroke and had recovered. However, in this population where contact with western style health services is infrequent, ascertainment for those with a history of stroke who had made a complete recovery would be unreliable without a longer and more complicated screening questionnaire. Verification would also be much more difficult and unreliable than in those patients in whom there was a residual deficit. In fact only eight patients were identified as having had a stroke from which they had made a complete recovery.

Although we can be relatively sure about the diagnosis in the cases that we did see with residual disability or impairment the numbers may be a slight underestimate of the true levels.

Our estimates of age are as accurate as possible in such a population where birth certificates are almost non-existent. With the methods used to estimate age a phenomenon of "age heaping" tends to occur where ages have a tendency to be rounded up or down by people to the nearest 5 years. When our results were compared with the age of the people as recorded in the yearly census data (for which the same methods are used) they showed good agreement.

We were not able to perform a validation study in this population of the questions used and cannot, therefore, quote rates for sensitivity and specificity of the questions. A recent United Kingdom study to validate a postal questionnaire for assessing the prevalence of stroke $^{15}$ found that the question "have you ever had a stroke?" had a sensitivity of $95 \%$ and a specificity of $96 \%$. Although it is hard to extrapolate from a postal questionnaire in a United Kingdom population to a house to house survey in a rural Tanzanian population it is likely that the question "is there anyone in the household with a history of stroke?" would have a high sensitivity although the specificity is likely to be considerably less. It is worth noting that kiharusi, the Swahili word for stroke, is also used by some people for other disorders associated with the brain, such as Parkinson's disease. The questions were asked in the appropriate local languages and the enumerators had been educated at workshops about the type of patients they were looking for. Further patients with residual impairment or disability relating to stroke were not found by the additional secondary measures which was reassuring with respect to the efficiency of the case ascertainment by the enumerators and suggests that the sensitivity of the methods was high. Feedback about the results was provided to the staff of the project at the end of the study and the enumerators have asked about prevalent stroke cases in the 4 yearly censuses since then. Further cases have been identified but none of these was living in the area with a prevalent impairment or disability from stroke at the time of the study.

Ideally we would have liked to have examined a sample of the "negative" questionnaire patients to be sure they did not have stroke related disability but, as the "stroke rate" is low, this sample would have to be very large and was not feasible.

Undoubtedly non-hemiplegic strokes with, for example, disability limited to speech or visual problems, and posterior circulation strokes with, for example, symptoms restricted to balance problems, will have been missed as specific questions to identify these problems were not used. Cognitive impairment was also not assessed. However, overall, it is likely that few of the disabled patients with strokes who were left with limb weakness were missed, and it is known from studies in developed countries that most patients disabled from stroke do have residual limb weakness. To ensure full and accurate completion of the questionnaire question 3 was deliberately kept simple and did not include all the activities of daily living as assessed by the Barthel index. However, we think that in conjunction with the other questions most people disabled by stroke will have been picked up.

As each case was seen and examined by one of us to confirm or refute the diagnosis of stroke this excluded interobserver errors in the making of the diagnosis. We are therefore confident that false positive patients are unlikely, although bearing in mind that brain CT was not available. If hemiplegia is due to malignancy then without treatment the neurological deficit is usually progressive and subsequently fatal. Infectious causes are more numerous in this region compared with developed countries and include such diagnoses as tuberculoma, gumma, echinococcus cysts, and AIDS. With these conditions there are likely to be other signs and symptoms and without treatment the disease is likely to be progressive.

As expected, the main impact of stroke is in the older age groups although, with the few stroke patients in this study, the confidence intervals are wide.

One explanation of the lower prevalence is likely to be increased case fatality for strokes in a country where medical and rehabilitation services are limited. Only 13 patients had had any regular physiotherapy. No data are, however, available for case fatality for stroke in this area.

A recent paper ${ }^{3}$ described the prevalence of stroke and stroke related disability in Auckland, New Zealand from two population based studies, one in 1981 with follow up of patients to 14 years, and the second in 1991-2 with 3 years of follow up. Using an actuarial model, they looked at overall stroke prevalence by age and sex and also prevalence for incomplete recovery and those needing help in at least one self care activity (washing, dressing, bathing, feeding, transferring, or toileting). Results for the three groups age standardised to the Segi World Population 15 years and over were respectively for men 991, 493, and 156; for women 706,448 , and 188 ; and for the group as a whole 833,461 , and 173 . Thus, the rates for those needing help in activities of daily living were a little higher than those found in this study (tables 1,2). 
From the Auckland study $20 \%$ of stroke survivors required assistance with at least one activity, most ( $60 \%)$ of whom required institutional care. Institutional care is not available in this area but there is a great respect for elders and an acceptance that disabled people should be looked after by their families. Some severely disabled patients had survived.

There are few data on stroke in the community in sub-Saharan Africa. In a study from central Ethiopia, ${ }^{16}$ between 1986 and 1988, a door to door survey was conducted on a stable rural population of 60820 . Thirty eight patients were found to have hemiparesis but in only nine was this thought to be secondary to cerebrovascular accident (15 cases/100 000).

A research protocol for measuring the prevalence of neurological disorders in developing countries was established in a pilot study of 903 patients in a rural community in Nigeria. ${ }^{17}$ This incorporated a screening questionnaire and simple neurological examination by "nondoctor health care workers" with subsequent examination by a neurologist of patients positively identified as having a potential neurological illness. Using this, 18594 patients were screened in a small town of $20000,{ }^{18}$ and 11 patients with disabilities relating to stroke were identified, giving a crude point prevalence ratio for stroke of $58 / 100000$. It should be noted that two of these patients were under the age of 10 and the "stroke" was thought to be secondary to sickle cell disease.

There are even fewer data on the natural history of stroke in sub-Saharan Africa. A study from Pretoria, South Africa, ${ }^{19}$ which included brain CT, followed up 116 consecutive patients with stroke admitted to hospital and reported a $33.6 \% 1$ month case fatality rate $(22.4 \%$ for those with cerebral infarction and $58 \%$ for those with cerebral haemorrhage). This reflects a patient group admitted to hospital and the proportion of those patients with a stroke admitted to hospital in sub-Saharan Africa is likely to be lower than in developed countries.

In developed countries, studies looking at outcome have largely assessed cohorts of patients with incident stroke longitudinally, at set intervals (usually 6 or 12 months) after the acute event. In the Frenchay Stroke Project 976 community stroke patients were assessed at 6 months and $53 \%$ were partially or totally dependent for activities of daily living. ${ }^{2}$ In the Oxfordshire Community Stroke Project 45\% of stroke victims were independent at 1 year. ${ }^{20}$

Most other studies have only followed up patients discharged from hospital after an acute stroke. ${ }^{21}{ }^{22}$ Even in developed countries up to one third of patients with stroke are never admitted to hospital and therefore these figures will underestimate the disability in the population. ${ }^{23}$ There has been a wide variation in reported levels of disability in stroke survivors which is explained partly by the use of many different outcome measures and also the varying times of assessment after stroke.

Increasing age is the strongest risk factor for cerebral infarction, primary intracranial haemorrhage, and subarachnoid haemorrhage. ${ }^{24}$ In studies from developed countries there is a small increased risk of stroke in men, ${ }^{25}$ most prominent in middle age and disappearing in the very elderly people, and absent in the young. However, as more women survive to old age, more women have strokes.

Previous studies relating to stroke in subSaharan Africa have shown that, in those admitted to hospital, males outnumber females by $2: 1$ and it has been suggested that this is because women are less likely to go to hospital rather than a true reflection of a major difference in incidence. ${ }^{26}$

In addition to showing that the younger patients with strokes were more likely to have had a good outcome, our data show that the women were generally more disabled and dependent than the men. This, unlike in developed countries, cannot be explained by increased numbers of women in the older age bands of the population as the proportions were relatively equal. The apparent relative survival advantage in males in the population as a whole may be due in part to high maternal mortality rates, although despite this, in the maternal age range all cause mortality rates are higher for men than women. ${ }^{13}$ The main reason is likely to be the lack of ischaemic heart disease which causes higher mortality in developed countries and is more likely to affect men than women, particularly in the younger age groups.

In developed countries ischaemic heart disease is common among stroke patients and in those who initially survive their stroke it is responsible for half of all deaths at follow up. ${ }^{27}$ However, ischaemic heart disease is rare in rural Africa as are other markers of atheroma. ${ }^{28}$ Our population has previously been shown to have a low prevalence of risk factors for coronary heart disease, ${ }^{29}$ and previous surveys in the area have shown that patients giving a history of angina or myocardial infarction are virtually non-existent. Without a high prevalence of other risk factors high blood pressure remains the main identifiable risk factor (apart from age) in this population.

Data from studies looking at prevalence of hypertension in sub-Saharan Africa show a wide variation $^{30}$ with generally a higher prevalence of hypertension in urban than rural populations of the same ethnic origin. Previous data from surveys within the AMMP areas have shown rates of hypertension of $10.9 \%$ in Hai. ${ }^{29}$

An increase in blood pressure, both diastolic and systolic, within a healthy population is strongly associated with subsequent stroke risk $^{31}$ whereas treatment of hypertension reduces stroke risk. ${ }^{32}$ Treatment of blood pressure is therefore the main risk factor modification applicable in this population as a whole, and in individual patients. However, the costs of antihypertensive treatment, which include case finding and monitoring, in addition to the cost of the treatment itself are often prohibitive in developing countries. This is the main reason for the high antihypertensive treatment default rates found in previous African stroke studies. $^{28}$ 
Even if efforts to treat hypertension to prevent strokes in sub-Saharan Africa are successful, the demographic transition will inevitably bring with it a major increase in the incidence of stroke, and along with this the prevalence of disability relating to stroke. At present these patients are looked after at home by their relatives, and while numbers are small this will continue, but increasing numbers of dependent elderly people are likely to be a major burden on this care structure.

Funding for the adult morbidity and mortality project is provided by the Department for International Development on behalf of the United Kingdom government and also by the Government of Tanzania. RW was funded for this specific project by the University of Newcastle upon Tyne and the Sandoz Foundation for Gerontological research (Regional Committee for Australia, New Zealand, Asia, Africa, Middle East), Regional Committee Secretariat, Sandoz Foundation for Gerontological Research, 54 Waterloo Road, (PO Box 101), North Ryde, New South Wales 2113, Australia. We acknowledge the staff of the adult morbidity and mortality project, Mrs Carrie Walker for her help with writing the computer programme and data entry, and Mrs Christine Mannighan for secretarial assistance.

1 Martin J, Meltzer H, Elliot D. Office of Populations, Censuses and Surveys Survey of disabilities and health problems. London: OPCS, 1988.

2 Wade DT, Langton-Hewer RL. Functional abilities after stroke; measurement, natural history and prognosis. $7 \mathrm{Neu}$ rol Neurosurg Psychiatry 1987;50:177-82.

3 Bonita R, Solomon N, Broad JB. Prevalence of stroke and Bonita R, Solomon N, Broad JB. Prevalence of stroke and stroke-related disability. Estimates from
stroke studies. Stroke 1997;28:1898-902.

4 Aho K, Reunanen A, Aromaa A, et al. Prevalence of stroke in Finland. Stroke 1986;17:681-6.

5 Sorensen PS, Boysen G, Jensen G, et al. Prevalence of stroke in a district of Copenhagen. Acta Neurol Scand 1982;66:68-81.

6 Whisnant JP, Fitzgibbons JP, Kurland LT, et al. Natural history of stroke in Rochester, Minnesota, 1945-54. Stroke 1971;2:11-22.

7 Matsumoto N, Whisnant JP, Kurland JP, et al. Natural history of stroke in Rochester, Minnesota, 1955-69. Stroke 1973;4:20-9.

8 Christie D. Prevalence of stroke and its sequelae. Med F Aust $1981 ;$ ii: $182-4$.

9 Reggio A, Walter AR, Patti F, et al. Prevalence of stroke: a door-to-door survey in three Sicilian municipalities. door-to-door survey in three
Neuroepidemiology 1996;15:92-102.

10 Bharucha NE, Bharucha EP, Bharucha AE, et al. Prevalence of stroke in the Parsi community of Bombay. Stroke 1988; of stroke in

11 Razdan S, Koul RL, Motta A, et al. Cerebrovascular disease in rural Kashmir, India. Stroke 1989:20:1691-3.

12 Bamford J, Sandercock P, Dennis M, et al. A prospective study of acute cerebrovascular disease in the community: the Oxfordshire community stroke project 1981-6. 1 Methodology, demography and incident cases of first-ever stroke. $\mathcal{F}$ Neurol Neurosurg Psychiatry 1988;51:1373-80.
13 Kitange HM, Machibya H, Black J, et al. Outlook for survivors of childhood in sub-Saharan Africa: adult mortality in Tanzania. BMF 1996;312:216-20.

14 WHO MONICA project PI. The World Health Organization MONICA project (monitoring trends and determinants in cardiovascular disease): a major international collaboration. 7 Clin Epidemiol 1988;41:105-14.

15 O'Mahony PG, Dobson R, Rodgers H, et al. Validation of a population screening questionnaire to assess prevalence of stroke. Stroke 1995;26:1334-7.

16 Tekle-Haimanot R, Abebe M, Gebre-Mariam A, et al. Community-based study of neurological disorders in rural central Ethiopia. Neuroepidemiology 1990;9:263-77.

17 Osuntokun BO, Schoenberg BS, Nottidge VA, et al. Research protocol for measuring the prevalence of neurologic disorders in developing countries. Results of a pilot study in Nigeria. Neuroepidemiology 1982;1:143-53.

8 Osuntokun BO, Adeuja AOG, Schoenberg BS, et al. Neurological disorders in Nigerian Africans: a community-based study. Acta Neurol Scand 1987;75:13-21.

19 Rosman KD. The epidemiology of stroke in an urban black population. Stroke 1986;17:667-9.

20 Dennis MS, Warlow CP. Stroke: incidence, risk factors and outcome. Br F Hosp Med 1987;194-8.

21 Greveson GC, Gray CS, French JM, et al. Long-term outcome for patients and carers following hospital admission for stroke. Age Ageing 1991;20:333-44.

22 Thorngren $M$, Westling B, Norrving B. Outcome after stroke in patients discharged to independent living. Stroke 1990;21:236-40.

23 Bamford JM, Sandercock PAG, Warlow CP, et al. Why are patients with acute stroke admitted to hospital? The experience of the Oxfordshire community stroke project. BMF 1986;292:1369-72

24 Bamford J, Sandercock P, Dennis M, et al. A prospective study of acute cerebrovascular disease in the community: the Oxfordshire community stroke project, 1981-6. Incidence, case fatality rates and overall outcome at 1 year of cerebral infarction, primary intracerebral and subarachnoid haemorrhage. F Neurol Neurosurg Psychiatry 1990;53: $16-22$.

25 Haberman S, Capildeo R, Rose FC. Sex differences in the incidence of cerebrovascular disease. F Epidemiol Community Health 1981;35:45-50.

26 Osuntokun B. Epidemiology of stroke in blacks in Africa. Hypertens Res 1994;17(supp 1):S1-10.

27 Dennis MS, Burn JPS, Sandercock PAG, et al. Long term survival after first-ever stroke: the Oxfordshire community stroke project. Stroke 1993;24:796-800.

28 Walker R. Hypertension and stroke in sub-saharan Africa. Trans R Soc Trop Med Hyg 1994;88:609-11.

29 Swai ABM, McLarty DG, Kitange HM, et al. Low prevalence of risk factors for coronary heart disease in rural Tanzanians. Int $\mathcal{F}$ Epidemiol 1993;22:651-9.

30 Nissinen A, Bothig S, Granroth $\mathrm{H}$, et al. Hypertension in developing countries. World Health Stat Q 1988;41:141-52.

31 Shaper AG, Phillips AN, Pocock SJ, et al. Risk factors for stroke in middle aged British men. BMF 1991;302:1111-5.

32 Collins R, Peto R, MacMahon S, et al. Blood pressure, stroke, and coronary heart disease. Part 2, short-term reductions in blood pressure: overview of randomised drug trials in their epidemiological context. Lancet 1990;335: 827-38. 